\title{
X-ray laser studies using plasmas created by optical field ionization
}

\author{
K.M. Krushelnick a), W. Tighe, and S. Suckewer \\ Princeton University Plasma Physics Labor atory, P.O. Box 451, Princeton, New Jersey, 08544
}

\begin{abstract}
$\mathrm{X}$-ray laser experiments involving the creation of fast recombining plasmas by optical field ionization of preformed targets were conducted. A nonlinear increase in the intensity of the 13.5nm Lyman- $\alpha$ line in Li III with the length of the target plasma was observed but only for distances less than the laser confocal parameter and for low plasma electron temperatures. Multiphoton pumping of resonant atomic transitions was also examined and the process of multiphoton ionization of FIII was found to be more probable than multiphoton excitation.
\end{abstract}

PACS numbers: 42.55.Vc, 52.70.La, 52.40.Nk, 52.25.Ns)
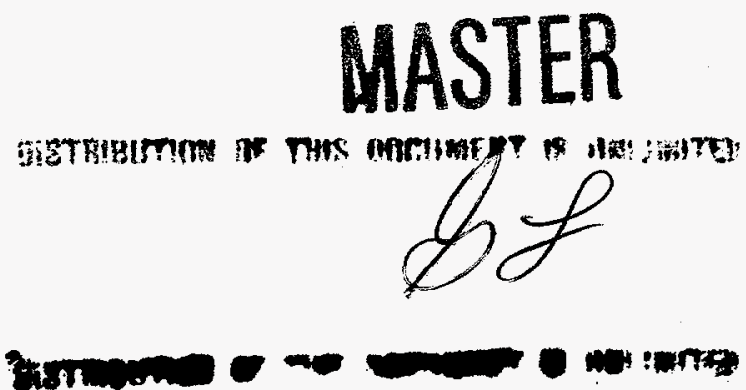

note: This paper has been submitted to Phys. of Plasmas

a) present address, Cornell University Dept. of Phys. Ithaca, NY 


\section{INTRODUCTION}

The use of intense laser pulses $\left(>10^{16} \mathrm{~W} / \mathrm{cm}^{2}\right)$ to create plasmas that can provide a medium for the production of coherent $\mathrm{x}$-rays has been the subject of much theoretical investigation in the last several years. Recent advances in laser technology have also enabled experimentalists to test some of these proposals.

At Princeton University experiments were undertaken using the high power PSPL (Powerful SubPicosecond Laser) system ${ }^{1}$ and two separate models for the creation of gain in the soft $\mathrm{x}$-ray region were examined.

These investigations: i) optical field ionization (OFI) to create a channel of fast recombining plasma ${ }^{2}$ and ii) resonant multiphoton excitation to populate upper levels of lasing transitions in a highly ionized plasma ${ }^{3}$, have been the subject of previous theoretical work. While the mechanisms for the production of gain in these situations are quite different, both ideas rely on the interaction of intense subpicosecond laser light with a preformed plasma, which was created in these studies by a relatively low power Nd:Glass laser system. Certain common technical issues such as the temporal and spatial alignment of the two laser systems as well as experimental questions concerning how the intense subpicosecond laser pulse interacts with an underdense plasma created by the Nd:Glass laser needed to be clarified before systematic experiments were performed.

\section{RECOMBINATION OF OPTICAL FIELD IONIZED PLASMAS}

It has been proposed to adapt the successful recombination laser ${ }^{4}$ to higher density plasmas where high stages of ionization could be produced through the use of optical field ionization pumping $5,6,7$ as a way of creating gain on $x$-ray transitions below $200 \AA$. In this scheme a sufficiently intense laser beam, incident on a gas or a preformed plasma, completely ionizes the target atoms by optical field ionization. The created plasma has high electron density and low electron temperature - ideal conditions for recombination lasing since recombination processes will then preferentially populate levels with high principle quantum numbers. ${ }^{8}$ The rate for three-body recombination into an atomic level, $\mathrm{n}$, of a hydrogenic ion can be estimated using the following expression

$$
P_{c r} \approx A_{o} Z^{-6} N_{e}^{2}(n)^{6}\left(\frac{I_{p}}{k T_{e}}\right)^{2} \exp \left(\frac{I_{p}}{(n+1)^{2} k T_{e}}\right) c m^{-3} \sec ^{-1}
$$




\section{DISCLAIMER}

This report was prepared as an account of work sponsored by an agency of the United States Government. Neither the United States Government nor any agency thereof, nor any of their employees, make any warranty, express or implied, or assumes any legal liability or responsibility for the accuracy, completeness, or usefulness of any information, apparatus, product, or process disclosed, or represents that its use would not infringe privately owned rights. Reference herein to any specific commercial product, process, or service by trade name, trademark, manufacturer, or otherwise does not necessarily constitute or imply its endorsement, recommendation, or favoring by the United States Government or any agency thereof. The views and opinions of authors expressed herein do not necessarily state or reflect those of the United States Government or any agency thereof. 


\section{DISCLAIMER}

Portions of this document may be illegible in electronic image products. Images are produced from the best available original document. 
(see e.g. Ref. 9) where $\mathrm{N}_{\mathrm{e}}$ and $\mathrm{T}_{\mathrm{e}}$ are density and temperature of electrons, $\mathrm{I}_{\mathrm{p}}$ is ionization potential of hydrogenic ion, $Z$ is an atomic number, and $A_{O}$ is a constant $\left(A_{0}=1.4 \times 10^{-31} \mathrm{~cm}^{3} \mathrm{~s}^{-1}\right)$. The strong dependence on electron density and inverse dependence on electron temperature are evident from this formula. In fact, simulations of such experimental situations indicate that immediately after the termination of the pumping pulse, inversions should occur on both the 2-1 and 3-2 transitions in the hydrogen-like ion. Small signal gain then exists for a time on the order of the radiative lifetime of the lasing transition ( 30 picoseconds for the $2-1$ transition in $\mathrm{Li}$ III and $0.3 \mathrm{~ns}$ for the 3-2 transition). It is also possible to get "quasi-steady state" gain on the 3-2 transition for initially hotter plasmas as they expand and cool on the order of the recombination time. ${ }^{10}$ In such experiments (Fig. 1), the photon source must be very intense since a population inversion can only be created if the photoionization rate during the pulse (initial stage) is much higher than the process of recombination. A prerequisite for the production of plasmas having sufficiently fast cooling rates (after laser pulses) is the use of laser pulses with a fall time much shorter than the recombination time. Subpicosecond pulses fit very well for this application since the intensity rises and falls on timescales which can be less than 50 femtoseconds.

A further concern regarding the use of this approach for the production of lasing plasmas, is whether residual heating of the ionized electrons by the laser will cause a significant temperature rise, which would reduce the three-body recombination rate and destroy potential inversions. This can be caused by ponderomotive heating (which occurs when ionized electrons are accelerated by the ponderomotive potential of the electric field as they leave the region of the laser focus) or by a multiphoton process in which the ionized electrons absorb more photons than the minimum required for ionization (above threshold ionization). If the pulse is short enough the ionized electrons will not have time to leave the region of the laser focus during the pulse and the ponderomotive energy will thus be returned to the laser field. In a high density plasma the requirement for charge neutrality will also prevent movement of electrons out of the focal region. However, the extra average drift energy given to the ionized electrons during the ionization process - while small - has been calculated to be significant in determining whether the plasma parameters are adequate for recombination lasing to occur. 6

It is also possible that Raman scattering and inverse bremsstrahlung will occur and create a population of heated electrons that could be detrimental to the formation of an inversion. Short (subpicosecond) laser pulses should be advantageous since the heating rate from inverse bremsstrahlung is only about $10-30 \mathrm{eV}$ for picosecond length pulses and decreases as the intensity of the incident laser is increased (see Ref. 6). Since the growth rate for stimulated Raman backscatter is on the order of several femtoseconds, fast electrons could be produced in significant quantities. These electrons, however, would be too energetic to interact strongly with the lasing plasma. 
Calculations for inversions in the transient regime have been performed for an optical field ionized boron plasma ${ }^{6}$. The calculated inversion populations and small signal gains for both the 3-2 and the 2-1 transitions show that the electron temperature and density in the plasma are much less stringent for the creation of inversions between the 3 and 2 levels than those necessary for the 2-1 transition. These calculations are explicitly for boron plasmas but plasma conditions necessary for elements with smaller $Z$ should be similar if not somewhat easier to obtain (i.e. allowing lower electron densities).

Recently, in a related experiment, Nagata et al. ${ }^{11}$ at the RIKEN institute in Japan have reported very high gain $\left(20 \mathrm{~cm}^{-1}\right)$ on the $2-1$ resonance transition in hydrogenic lithium (135 $\AA$ ) but only for plasma lengths up to $2 \mathrm{~mm}$. The target plasma was created by a line-focused $20 \mathrm{~ns}$ $\mathrm{KrF}$ laser about $700 \mathrm{~ns}$ before interaction with a high intensity subpicosecond pump laser.

In an effort to answer some outstanding questions concerning these results and to confirm the observed gain, similar experiments were undertaken by Berkeley/Livermore ${ }^{12}$ and Princeton groups ${ }^{13}$. The RIKEN group reported gain at relatively low electron densities $\left(10^{17} \mathrm{~cm}^{-3}\right)$ and very low temperatures $(<3 \mathrm{eV})^{14}$, but the necessary conditions for lasing may be created in higher temperature and density plasmas as well, since similar recombination rates are achievable for a variety of plasma temperatures and densities. 6

However the intense laser beam suffered severe defocusing due to changes of electron density as a result of multiphoton ionization. The distance an intense pulse can travel without severe defocusing is given by 15

$$
\mathrm{L}_{\mathrm{mpi}} \sim(1 / 2) \lambda \mathrm{n}_{\mathrm{c}} / \delta \mathrm{n}_{\mathrm{e}}
$$

where $\lambda$ is the laser wavelength, $n_{c}$ is the critical density and $\delta n_{e}$ is the change in electron density due to optical field ionization. For $\delta n_{\mathfrak{e}} / n_{c} \sim 10^{-4}$ this gives a distance of about $2 \mathrm{~mm}$ for $248 \mathrm{~nm}$ light. For smaller amounts of plasma produced by optical field ionization (i.e. lower $\delta n_{e}$ ) this propagation distance will increase. 16

The experimental setup is shown in Fig. 2. A $1.0 \mathrm{~J}$ Nd:Glass laser irradiated a solid stepped lithium fluoride $(\mathrm{LiF})$ slab to create the target plasma. The pulse length of the Nd:Glass laser was approximately $12 \mathrm{~ns}$ and was focused to a $6 \mathrm{~mm}$ line ( $60 \mathrm{~cm}$ focal length). The length of the target plasma could be varied simply through the up-down movement of the stepped target without requiring a change in the alignment of the lasers. The stepped target was controlled by a 3-D vacuum manipulator. The focus of the subpicosecond laser pulse ( $330 \mathrm{fs}, 100-200 \mathrm{~mJ}$ ) was positioned at the center of the line focus of the Nd:Glass laser on the stepped target and the distance between the focal region and the edge of the stepped target was varied by adjustment of the target position (note that such movement did not significantly affect the intensity from the line focused laser). 
The alignment of the XUV spectrometer was critical since if gain existed it would only be observable if the entrance slit of the spectrometer was well aligned with both the line focus of the $\mathrm{Nd}$ :Glass laser and the focal volume of the picosecond laser system. A Helium-Neon laser was centered through the target chamber and onto the entrance slit of a $2.0 \mathrm{~m}$ XUV spectrometer (SOXMOS). ${ }^{17}$ The beam path of the $248 \mathrm{~nm}$ light was adjusted so that it exactly followed the path of the alignment laser, and the line focus of the $\mathrm{Nd}$ :Glass laser was adjusted so that it also overlapped the alignment laser.

Since the Nd:Glass laser was able to produce $\mathrm{x}$-ray signals detectable by the spectrometer, a high voltage gating system was installed on the microchannel plate detector of SOXMOS which had a "window" of about $20 \mathrm{~ns}$. This gating also served to indicate when $\mathrm{Li}^{2+}$ was the dominate species in the plasma and thus to determine the optimum time for triggering the ultra-high intensity laser pulse.

The gating for the detection system was always positioned around the subpicosecond laser pulse during these experiments. It was noted that if the production of plasma from the $\mathrm{Nd}$ :Glass laser was more than $100 \mathrm{~ns}$ before the center of the gating window little soft $\mathrm{x}$-ray emission was observed from the $\mathrm{Li}^{2+}$ ions at the 2-1 transition at $135 \AA$. It was also noted that significant fluorine emission in the $135 \AA$ region occurred only for times when the Nd:Glass laser was incident on the target and for briefly afterwards, while the observation of Li III emission caused by recombination occurred for about $100 \mathrm{~ns}$ after the Nd:Glass laser had formed the line-focused plasma ( $\mathrm{Li}$ II occurred for somewhat longer). The predominance of fluorine lines was then evidence of the production of a hot plasma in which fully stripped lithium ions had lower recombination rates and hence would recombine slower (note that in time-integrated spectra lithium emission greatly exceeded fluorine emission at these wavelengths).

For the experiments performed here - beyond a separation of about $300 \mathrm{~ns}$ - little production of $\mathrm{Li}$ III and $\mathrm{Li}$ II was observed due to ionization of the plasma by the intense subpicosecond pulse. This was in contrast to the experiments of the RIKEN group who used a separation of $700 \mathrm{~ns}$ between the two pulses. They observed no emission of $135 \AA \mathrm{Li}$ III created by the intense laser pulse until separations of $600 \mathrm{~ns}$. Their explanation was that the plasma density in the Li II plasma column was too high ( $\left.>10^{17} \mathrm{~cm}^{-3}\right)$ so that the process of multiphoton ionization led to defocusing of the laser light preventing further ionization. Such defocusing of intense laser light due to multiphoton ionization has been observed recently by Monot et al. 18 .

Because the conditions of the target plasmas from the RIKEN experiments were somewhat different from our experiments, the separation between initial creation of the plasma column and the interaction of the high intensity laser pulse was expected to be different. Since in our experiment a $1 \mu \mathrm{m} \mathrm{Nd:Glass} \mathrm{laser} \mathrm{was} \mathrm{used} \mathrm{to} \mathrm{create} \mathrm{the} \mathrm{target} \mathrm{plasma} \mathrm{column,} \mathrm{its} \mathrm{initial}$ 
density was somewhat lower than in the RIKEN experiment (in which a plasma column was created with a $\mathrm{KrF}$ excimer laser) due to a reduction of $\sim 16$ times in the critical density. The initial plasma temperature in our experiment should also be higher since the energy of the incident laser was 4-5 times larger (i.e more energy was deposited in a similar volume). This is consistent with the RIKEN group observation of no Li III from the line-focused laser alone while in our experiment the Nd:Glass laser produced a significant soft x-ray signal from Li III. This would cause a faster expansion rate with the result that lower densities would be created sooner. The temperature of the plasma column in this situation was probably higher than that in the RIKEN experiments. As discussed previously, this should cause a reduction of the gain.

While a laser pulse at $10^{17} \mathrm{~W} / \mathrm{cm}^{2}$ could be partially absorbed due to collisional absorption and heat the plasma electrons to about $30 \mathrm{eV}$ (Ref. 6), for $\mathrm{Li}$ III (at $\mathrm{n}_{\mathrm{e}}=10^{19} \mathrm{~cm}^{-3}$ ) the collisional ionization time at $30 \mathrm{eV}$ is about $6 \mathrm{~ns}$. This implies that the signal from Li III observed in these experiments was primarily due to $\mathrm{Li}^{3+}$ recombining after multiphoton ionization.

Additionally, multiphoton ionization of the fluorine atoms having a lower ionization potential than $\mathrm{Li}$ III might contribute to the defocusing effect. Since large amounts of Li III were created by multiphoton ionization this implies that significant quantities of fluorine ions were also produced (those having barrier suppression thresholds less than or equal to Li III, which includes all fluorine states up to F VII).

Using a temporal separation between the Nd:Glass laser and the subpicosecond laser of $150 \mathrm{~ns}$, experiments were performed with a Nd:Glass laser energy of $\sim 1.5 \mathrm{~J}$. It was noticed that population inversions occurred in the recombining plasma between levels 3-2, 4-3, and 5-4 (Fig. 3 ) in Li III for energies of the subpicosecond laser pulse which ranged from $100 \mathrm{~mJ}$ to $225 \mathrm{~mJ}$. While there were fluctuations in the laser energy and the degree of the recorded inversions in this experiment, it appeared that it was easier to obtain inversions between lower levels in Li III for higher energy shots. A higher multiphoton ionization rate would increase the plasma electron and $3+$ ion densities without increasing the plasma electron temperature since inverse bremsstrahlung heating scales inversely as the laser intensity $\left(\mathrm{I}^{-1 / 2}\right)$. For this reason higher energy pulses could contribute to increasing the subsequent three-body recombination rate. More data is required to support these observations.

Having demonstrated that inversions could be created in recombining lithium plasmas between levels 3 and 2 in the hydrogenic ions, the next step was to determine if inversions had been occurring transiently between the first excited level and the ground state (which is the desired goal). This requires the measurement of gain.

The energy of the line-focused laser was decreased to $\sim 1 \mathrm{~J}$ thereby reducing the initial temperature of the target plasma. This reduced the occurrence of population inversions in the 
recombining plasma. The dominant effect was a marked variation in the ratio of the 2-1 line to the 3-1 line with respect to the energy of subpicosecond laser beam. If the 2-1 line is much higher than the 3-1 line this may indicate that there is gain occurring on the 2-1 transition as the region where the necessary plasma conditions exists becomes larger. It might also only imply that as the subpicosecond laser energy is increased the population of the first excited level becomes enhanced with respect to other levels during the recombination process and that population inversion between this level and the ground state is increasingly likely.

Since the ratio of $114 \AA$ to $135 \AA$ varied markedly with laser energy this indicated that conditions could be optimized for higher beam intensity, which could produce denser plasmas (see Fig. 4) or perhaps a longer region of gain.

With the prospect that the conditions for gain had been attained for the 2-1 transition of Li III, gain should be measureable by varying the length of the target plasma column. First, the distance of the intense laser focus from the surface of the target was optimized to produce the maximum signal on the $135 \AA$ line. This distance was found to be $\sim 0.5 \mathrm{~mm}$. The target length was then changed from $0.5 \mathrm{~mm}$ to $4 \mathrm{~mm}$ in steps to observe if a nonlinear increase in the detected $135 \AA$ emission could be produced with these conditions (see Figs. 5, 6). It was found that since the target plasma conditions changed frequently and the pulse parameters of the subpicosecond laser changed from shot to shot, finding repeatable conditions for nonlinear increase in signal with plasma length was problematic. Some of this was probably due to slight changes in alignment of the two laser systems from one day to the next (since the alignment of the PSPL was never precisely the same on consecutive days) and variations in beam profile, focusing properties, and amplified spontaneous emission (ASE) versus short pulse energy. However, since for some alignments nonlinear growth was observed for short plasma lengths (i.e. less than the diffraction length of the laser focus $\sim 5 \mathrm{~mm}$ ) it may be that all that is needed to make such gain more reproducible is greater control over the parameters of the intense pulse and a more systematic and more precise method of aligning the gain region in the target plasma to the spectrometer slit.

Nevertheless, nonlinear increase was observed at temporal separations between the subpicosecond pulse and the Nd:Glass laser pulse of 150 ns with a variation in these measurements about $25 \%$. Nonlinear enhancement was shown for target lengths up to $2 \mathrm{~mm}$ after which defocusing of the laser pulse is expected to prevent further increase of the gain region.

These measurements were also repeated in hotter plasmas ( $\Delta \mathrm{t} \sim 100 \mathrm{~ns}$ ) but were subject to larger experimental error than that produced at separations of $150 \mathrm{~ns}$ and further work is required to define more precisely if and where gain conditions exist in these plasmas. 


\section{A. Discussion}

Many difficulties arise in the creation of population inversions and subsequent production and measurement of gain in experiments of this type.

Due to the rapid recombination rate (and other depopulation rates) to the ground state, $\mathrm{Li}$ ions must be completely stripped of electrons in a very short time (e.g. via multiphoton ionization using ultrashort laser pulses) in order to create inversions between the first excited level and the ground state of hydrogen-like Li III. Immediately following the laser pulse excited levels will be more populated than the ground state - but only for time periods dictated by the deexcitation and recombination (both three-body and photorecombination) rates to the ground state.

In the present experiment the size of the preformed plasma is large. There may be areas where lithium ions are not totally stripped of electrons (e.g. regions of lower laser intensities) and which therefore have a high density of Li III in the ground state creating a highly absorbent region that would reduce gain very significantly. This suggests that the gain measured in the RIKEN experiment as well as that indicated by the present experiment could have been much higher if such absorption was eliminated.

In addition, the above gain measurements depend upon the assumption that the actual length of the plasma column with which the intense laser pulse interacts is about the same as the length of the line focus that produced it. This is true if the ablated plasma expands initially in only one direction (back towards the direction from which the laser came) so that expansion does not significantly increase the interaction length of the plasma. However, the line-focused plasma may expand horizontally by a significant amount so that the length used in the gain calculation would be underestimated and the gain-length would be overestimated.

To improve performance it is probably necessary that the gain region extend over longer distances than the confocal length of the high intensity laser focus. Channeling may be possible by temporally multiplexing the excimer pulses with $\Delta \mathrm{t} \sim 500$ ps such that the first pulse creates a channel having a parabolic electron density gradient ${ }^{19}$ or by using the poorly focused ASE component of the intense laser pulse to prepare an appropriate target plasma (with a density minimum on axis) as the laser is focused through a small hole in the target. For very intense lasers the light may even be self-focused by the relativistic motion of the ionized electrons. ${ }^{20}$

In summary, these experiments have confirmed that nonlinear increases in the 2-1 emission of Li III ions in optical field ionized recombining plasmas can be observed. Population inversions in the recombining plasma created by optical field ionization were definitely observed. However, reliable measurements of gain were not possible due to experimental uncertainties so that gain measurements in recombining lithium plasmas in the RIKEN experiment could not be verified. 


\section{RESONANT EXCITATION VERSUS IONIZATION}

Experiments were also carried out to search for resonant excitation of levels in a preformed plasma via multiphoton excitation. In this case it is necessary that the excitation energy be very close to an integer multiple of the $248.5 \mathrm{~nm}$ photon energy $(5 \mathrm{eV})$ and that the transition be dipole allowed (hence, for an odd number of laser photons) in order to enhance the population of the upper levels. Additionally, the resonant excitation rate must be much greater than the corresponding multiphoton ionization rate if this is to be a useful method for producing population inversions between ion transitions in the x-ray region.

Experiments were carried out using the subpicosecond laser pulse focused onto a $\mathrm{LiF}$ plasma. The population of the F III $2 \mathrm{p}^{2} 4 \mathrm{~d}$ level was observed with a gated XUV spectrometer located $0.8 \mathrm{~m}$ from the interaction region. An 11-photon (225.9 $\AA$ ) near resonance occurs for the F III $2 p^{3}-2 p^{2} 4 d$ transition at $226.1 \AA$. The coincidence for this transition is about $\Delta \lambda / \lambda \sim 6 \times 10^{-4}$, however better matching is achievable since the laser bandwidth is about $3 \AA$. Of course, the laser field can produce tremendous Stark shifts in the level structure as the laser beam interacts with the atom in the plasma, however if the Stark shift of both levels in the transition is comparable then resonant enhancement is possible. If multiphoton excitation of the upper (4d) level does occur, enhanced emission should be observable at $226.1 \AA, 243.3 \AA, 245.0 \AA$ and $235.8 \AA$ wavelengths (Fig. 7) with relatively less enhancement of other nonresonant F III lines or perhaps reduced emission of nonresonant lines resulting simply from loss of F III population by multiphoton ionization to higher ionization stages. Emission from the entire 4d manifold in F III may be enhanced due to collisional mixing of these levels in high density plasmas. It is also possible that emission at around $226.3 \AA$ may be due to high harmonic generation, but this would be correlated with adjacent harmonics.

The powerful subpicosecond laser, PSPL ( $>10^{17} \mathrm{~W} / \mathrm{cm}^{2}$ ) was focused on an expanding preformed LiF plasma created by a $1 \mathrm{~J} \mathrm{Nd:Glass} \mathrm{laser} \mathrm{and} \mathrm{spectra} \mathrm{were} \mathrm{recorded} \mathrm{in} \mathrm{order} \mathrm{to}$ measure the enhancement of ionization and to determine if resonant 11 photon pumping occurs.

In Fig. 8 spectra are shown indicating that the chief effect of the interaction of the PSPL with the preformed plasma target was an increase in the average ionization stage of fluorine and lithium. As a result the total F III emission declined substantially throughout this wavelength region, however only the intensity of those F III transitions that could not be pumped by the resonant excitation process declined (the F III transitions with reduced intensity were all from the $3 \mathrm{~d}$ manifold to the ground state). Those lines that had the potential for enhancement by resonant 11 photon absorption either increased in intensity or remained the same. This observation 
suggests that although multiphoton ionization may remain more probable than resonant excitation, significant enhancement by resonant multiphoton excitation does occur. (No direct measurement of the contribution of multiphoton ionization versus collisional ionization was made in these experiments.)

The spectra were also recorded during interaction of the PSPL with a lower density, cooler plasma, (i.e. there was a longer time delay between the creation of the plasma and the firing of the subpicosecond laser) - where no F III emission and very little Li III occur without the introduction of the intense subpicosecond laser pulse. In this case, (see Fig. 9) enhancement of the Li III 2-1 (135 $\AA$ ) and 3-1 (114 $\AA$ ) line emission was observed as well as an enhancement of F III line emission, but only on transitions whose upper levels could be populated by the 11 photon excitation process. This provided further evidence that a high order multiphoton excitation process was occurring.

\section{A. Discussion}

Since the intensity of the laser was large enough to cause substantial multiphoton ionization of the lithium-fluorine plasma one of the primary competing processes with the resonant population of excited levels in F III could be resonantly enhanced multiphoton ionization. The resonantly excited states examined in this experiment were only $15 \mathrm{eV}$ from the continuum so it is possible that this phenomenon significantly reduced the effect of resonant excitation on the populations of excited levels in the plasma ions. However, since the population of the $4 \mathrm{~d}$ manifold was strongly increased, this provides evidence that an 11-photon excitation process was occurring. It is not clear if such enhancement occurred primarily during the lower intensity regions at the edge of the pulse where the multiphoton ionization rate is lower and the Stark shifts of atomic levels are also much smaller.

Because of the high intensity of the laser used in these experiments, multiphoton ionization is clearly more prevalent than multiphoton excitation. This agrees with previous theoretical work. ${ }^{21}$ However, if the resonant state is further from the continuum than in the situation examined here, the effect of multiphoton excitation should be more pronounced. 


\section{ACKNOWLEDGMENTS:}

We would like to thank L. Polonski and C.O. Park for help in operating the Nd:Glass laser and N. Tkach and D. DiCicco for technical assistance. We would also like to thank R. Falcone for providing valuable discussion concerning the RIKEN experiments. Support for final year of K. Krushelnick's graduate studies was provided by LLNL and PPPL. This work was partially supported by the US Department of Energy Contract No. DE-AC02-76CHO30703. 


\section{REFERENCES}

${ }^{1}$ L. Meixler, C.H. Nam, J. Robinson, W. Tighe, K. Krushelnick, S. Suckewer, J. Goldhar, Opt. Soc. Am.Proc., "Short Wavelength Coherent Radiation: Generation and Applications, "Vol.2, Falcone and Kirz (eds.), Cape Cod, MA., pg.106-115 (1989)

${ }^{2}$ W.W. Jones and A.W. Ali, Appl. Phys. Lett. 26, 450 (1975)

${ }^{3}$ C. Clark, M.G. Littman, R. Miles, T.J. McIlrath, C.S. Skinner, and S. Suckewer, J. Opt. Soc. Am. B 3, 371 (1986)

${ }^{4}$ S. Suckewer, C. Skinner, H. Milchberg, C. Keane, and D. Voorhees, Phys. Rev. Lett. 55, 1753 (1985)

5 P. Amendt, D.C. Eder and S.C. Wilks, Phys. Rev. Lett. 66, 2589 (1991)

${ }^{6}$ N.H. Burnett and G.D. Enright, IEEE J. Quant. Elect. QE-26, 1797 (1990)

7 J. Peyraud and N. Peyraud, J. Appl. Phys. 43, 2993, (1972)

8 W.W. Jones and A.W. Ali, Appl. Phys. Lett. 26, 450, (1975)

${ }^{9}$ R.C. Elton, X-Ray Lasers, Academic Press Inc., San Diego CA, (1990).

10 C. Keane, in "Femtosecond to Nanosecond High Intensity Lasers and Applications", E. Campbell (ed.), Los Angeles.

11 Y. Nagata, K. Midorikawa, M. Obara, H. Tashiro and K. Toyoda, Phys. Rev. Lett. 71. 3774 (1993).

12 R. Falcone, Private communication (July 1993); T. Donnelly et al., 4th International Colloquium on X-Ray Lasers, Williamsburg, VA., May 16-20 (1994), (Proceedings in press).

${ }^{13}$ L.Y Polonsky, C.O. Park, K. Krushelnick, and S. Suckewer, Proc. SPIE Conference on Ultrashort Wavelength Lasers II (S. Suckewer ed.), Vol. 2012, 75 (1993).

$14 \mathrm{~K}$. Midorikawa et al., 4th Inter. Colloquium on X-Ray Lasers, Williamsburg, VA, May 16-20, (1994), (proc. in press).

15 E. Mevel, P. Breger, R. Trainaham, G. Petite, P. Agostini, A. Migus, J. P. Chambaret and A. Antonetti, Phys. Rev. Lett. 70, 4, 406 (1993).

16 S. Augst, D. Strickland, D.D. Meyerhofer, S.L. Chin and J. H. Eberly, Phys. Rev. Lett. $\underline{63}$, 2212 (1989).

17 J. L. Schwob, A. Wouters and S. Suckewer, Rev. Sci. Inst. 58, 1601 (1987).

18 P. Monot, T. Auguste, L.A. Lompre, G. Mainfray, and C. Manus, J. Opt. Soc. Am .B.9, 9, 1579 (1992).

19 C.G. Durfee III and H.M. Milchberg, Phys. Rev. Lett. 71, 15, 2409 (1993).

20 P. Sprangle, E. Esarey, J. Krall, and G. Joyce, Phys. Rev. Lett. 69, 15, 2200 (1992).

21 S. Susskind, E.Valeo and C. Oberman, Phys. Rev. A 43, 2569 (1991). 


\section{Figure Captions}

FIG. 1 Schematic of $\mathrm{x}$-ray lasing during recombination of an optical field ionized plasma (Note: the Rayleigh length is the diffraction length for a focused gaussian beam given by $\pi w^{2} / \lambda_{L}$, but the intense beam could be maintained over longer distances by channeling processes)

FIG. 2 Experimental setup for two-laser experiments using recombining LiF plasmas (stepped target as inset)

FIG. 3 Population inversions in hydrogenic lithium A) between levels 3 - 2 (energy of PSPL $200 \mathrm{~mJ}$ ) B) between levels 4 - 3 (energy of PSPL $150 \mathrm{~mJ}$ ) C) between levels 5-4 and 5-3 (energy of PSPL $\sim 100 \mathrm{~mJ}$, energy of Nd:Glass laser was similar $(\sim 1.5 . \mathrm{J})$ in all three spectra)

FIG. 4 Variation of Li III signal with respect to energy of PSPL pulse - note although 2-1 transition increases substantially 3-1 does not.

FIG.5 X-ray emission from recombining optically ionized LiF plasma for $\Delta t=150 \mathrm{nsec}$. Energy of Nd:Glass laser was $\sim 1.0 \mathrm{~J}, \quad$ A) $1 \mathrm{~mm} \quad$ B) $2 \mathrm{~mm} \mathrm{C)} 4 \mathrm{~mm}$.

FIG. 6 Variation in emitted $x$-ray signal from 2-1, 3-1, and 4-1 transitions in hydrogenic lithium (Fig. 5, $\Delta \mathrm{t} \sim 150 \mathrm{nsec}$ ). A nonlinear increase is observable for short lengths while emission does not seem to increase for long target lengths.

FIG. 7 Grotrian diagram for F III in region around 11 photon resonance of $248.5 \mathrm{~nm}$. 
FIG. 8 Spectra showing enhancement of soft $\mathrm{x}$-ray emission due to interaction of PSPL pulse with preformed LiF targets. The average ionization state is clearly much increased for fluorine and the amount of $\mathrm{Li}$ III is also greatly increased A \&B) preformed plasma without high intensity laser interaction $C \& D$ ) with high powered subpicosecond laser interaction at $5 \times 10^{17} \mathrm{~W} / \mathrm{cm}^{2}$ Closer view of spectra presented in Fig. 8 B) and D) showing shaded lines which may be enhanced by a resonant multiphoton excitation of the upper level.

FIG. 9 Emission for optical field ionized plasma in same region as Fig. 8 but for cooler LiF target plasma (delay was $150 \mathrm{nsec}$ ). The strongest lines of F III are those which should be produced by 11 photon resonant excitation and are shaded. 


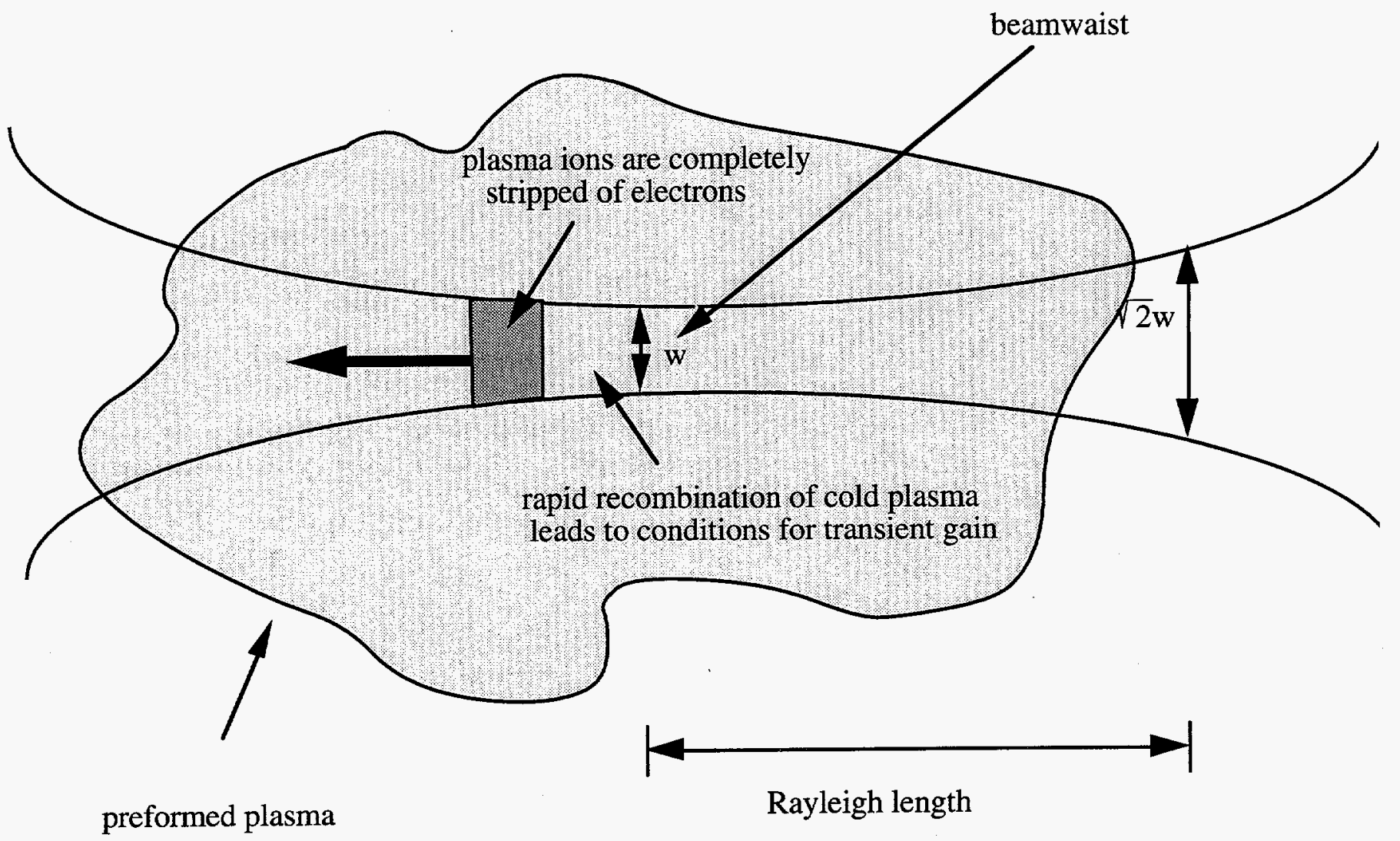

Figure 1. 


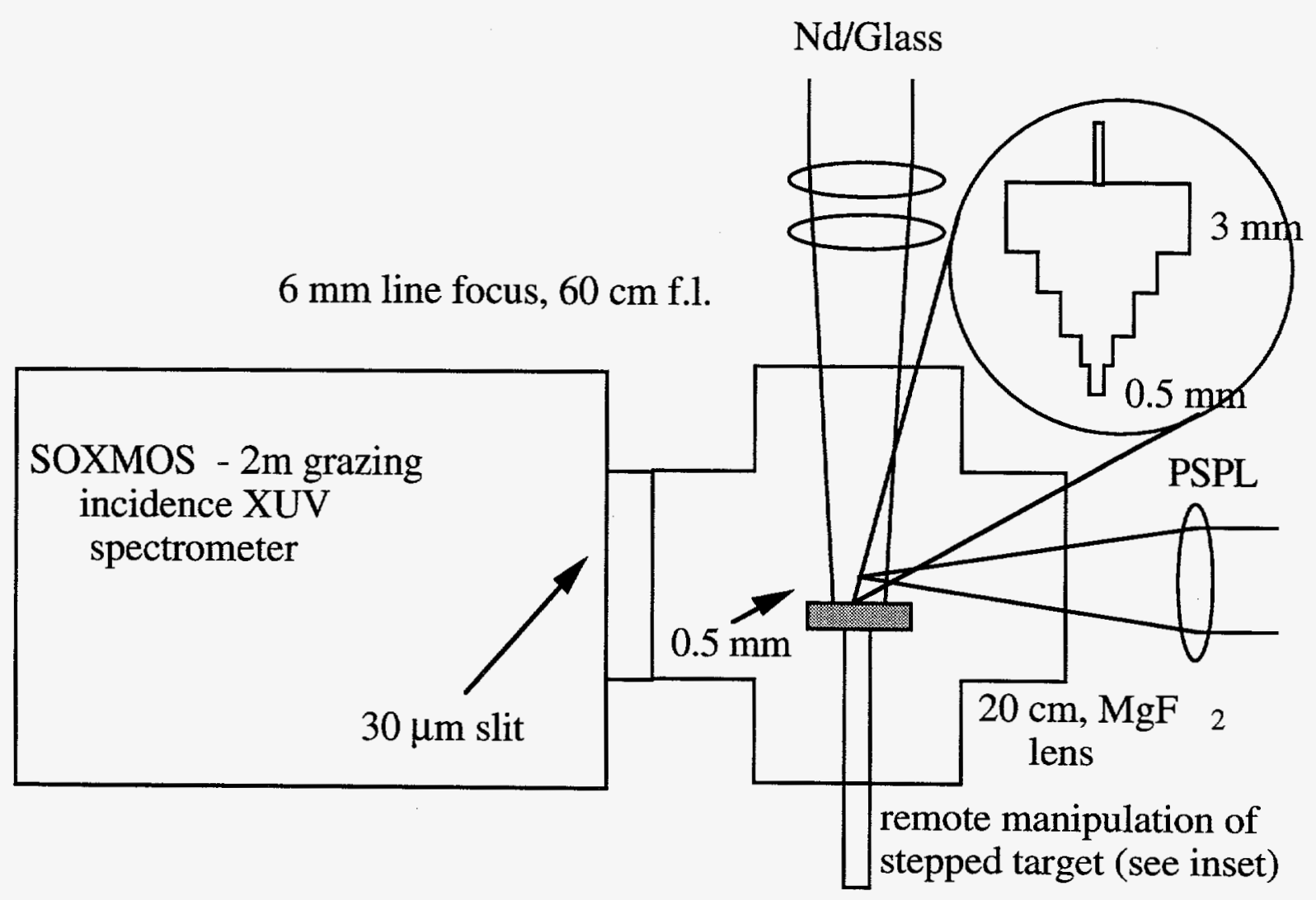

Figure 2. 


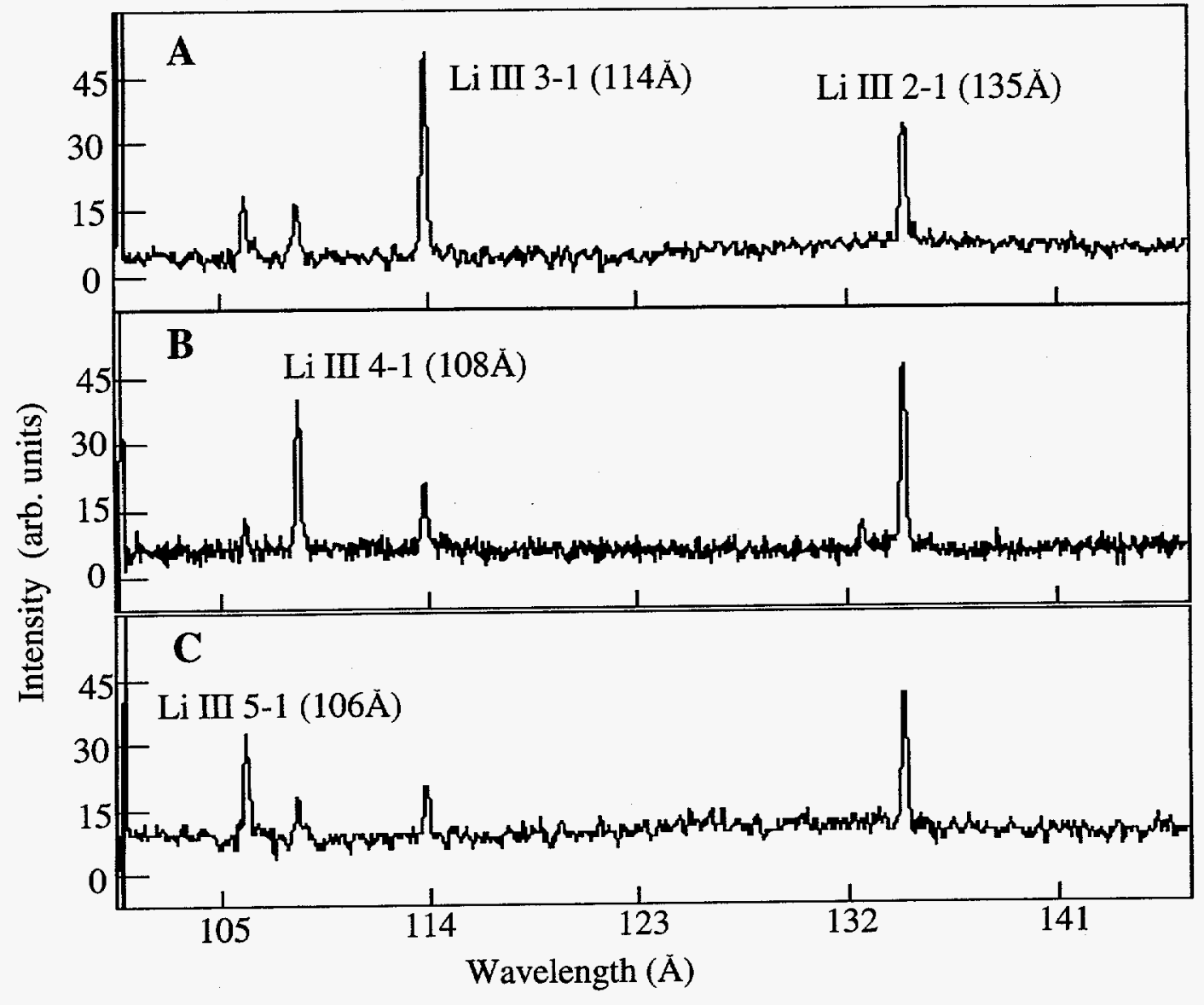

Figure 3. 


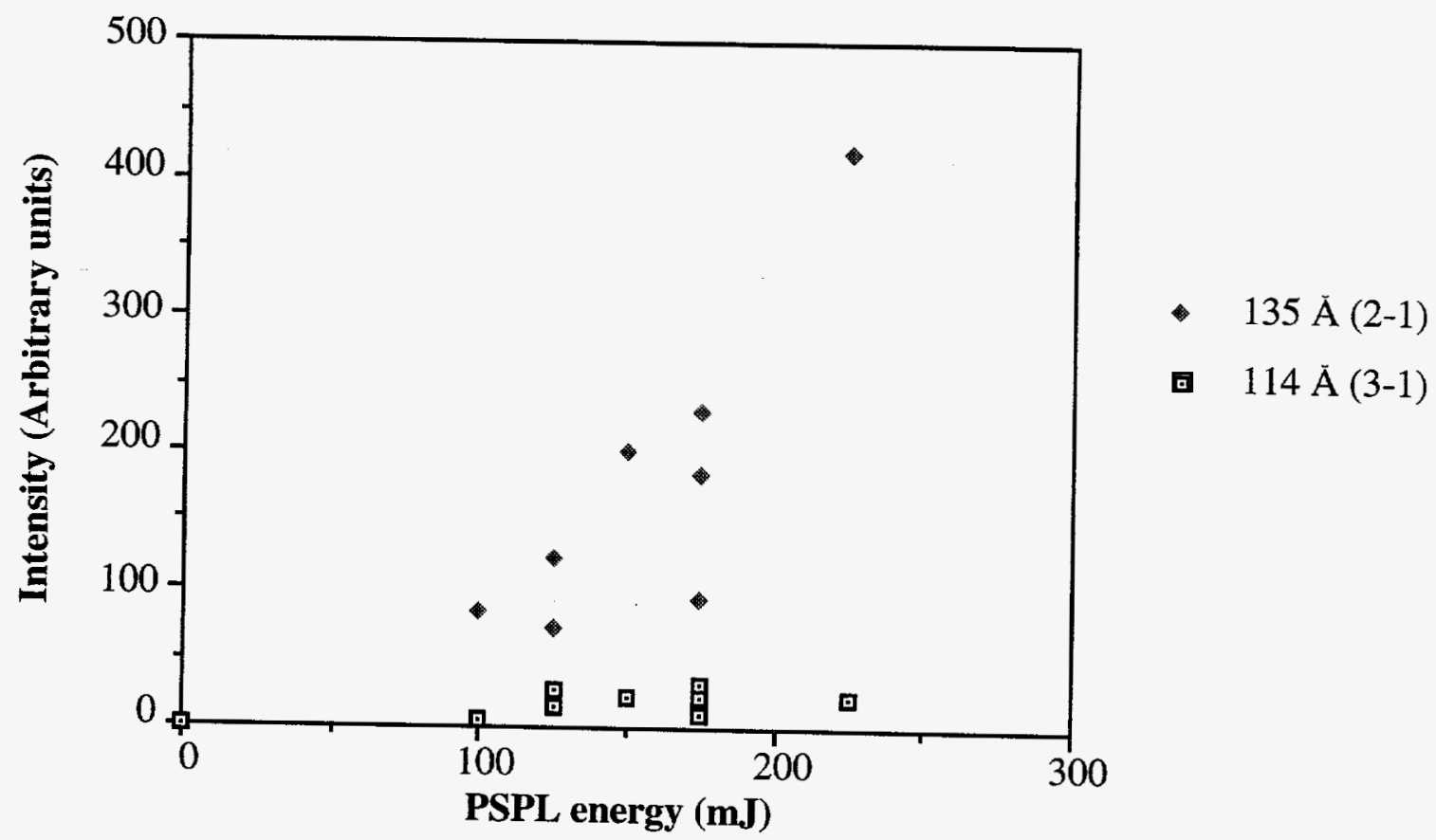

Figure 4. 


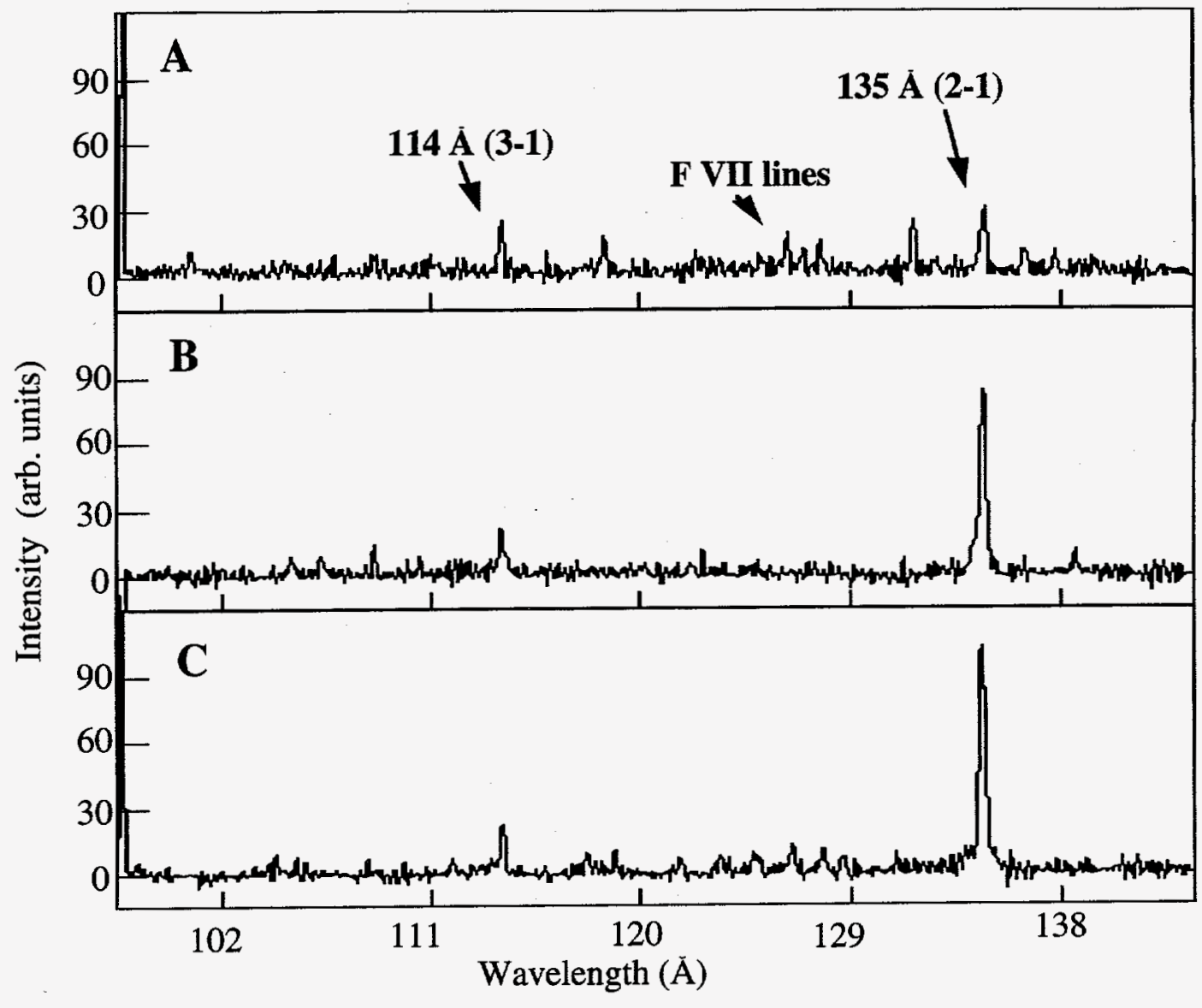

Figure 5. 


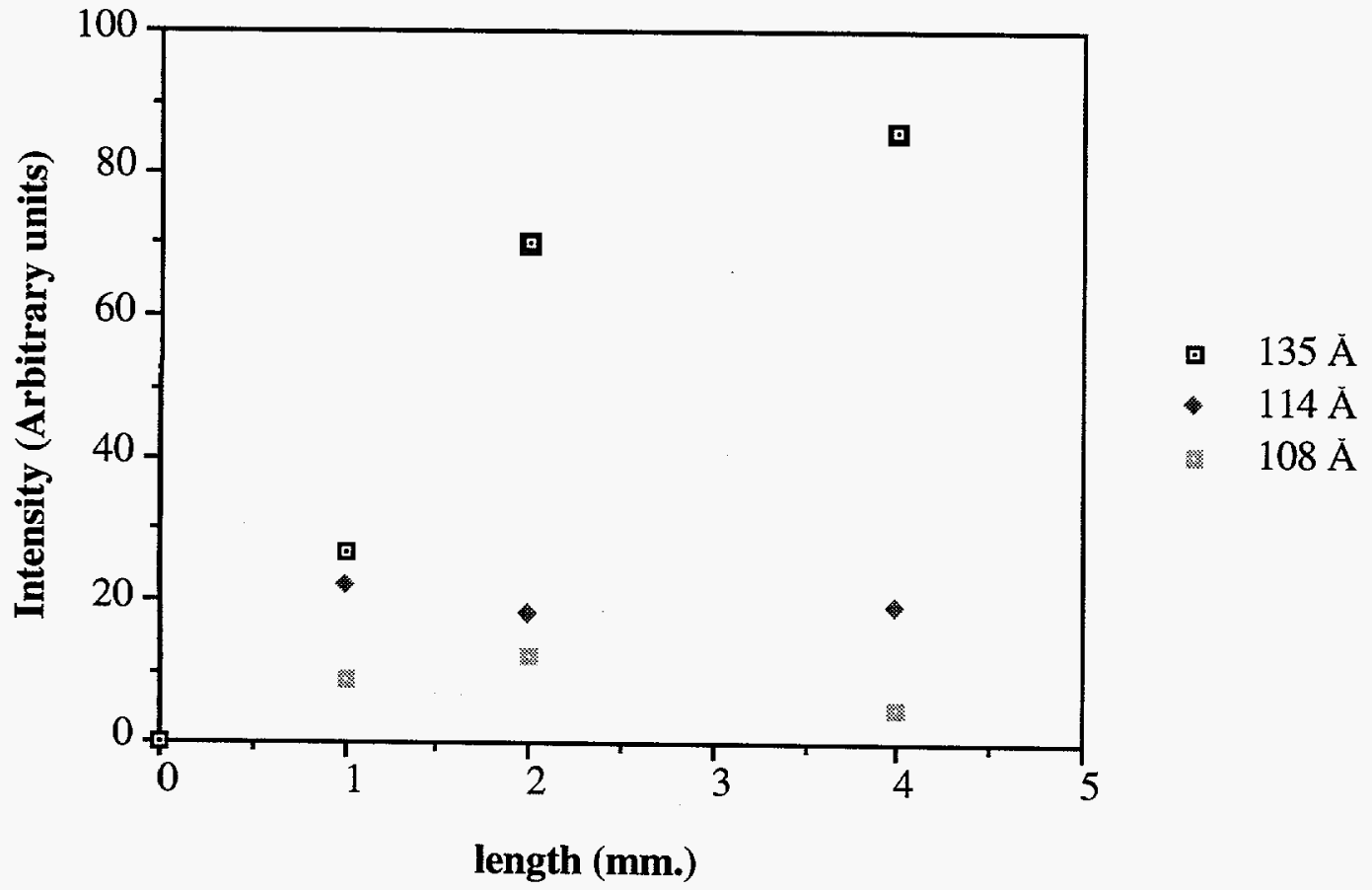

Figure 6. 


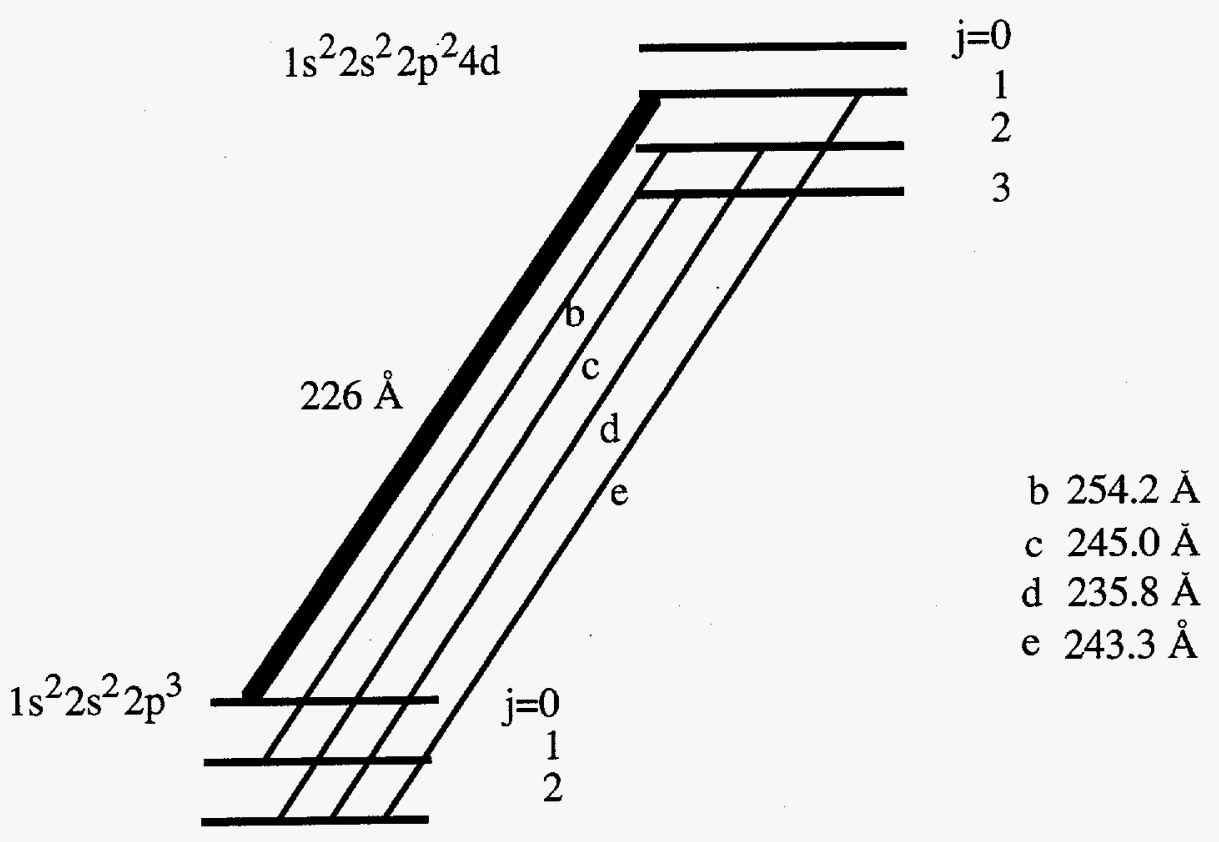

Figure 7. 


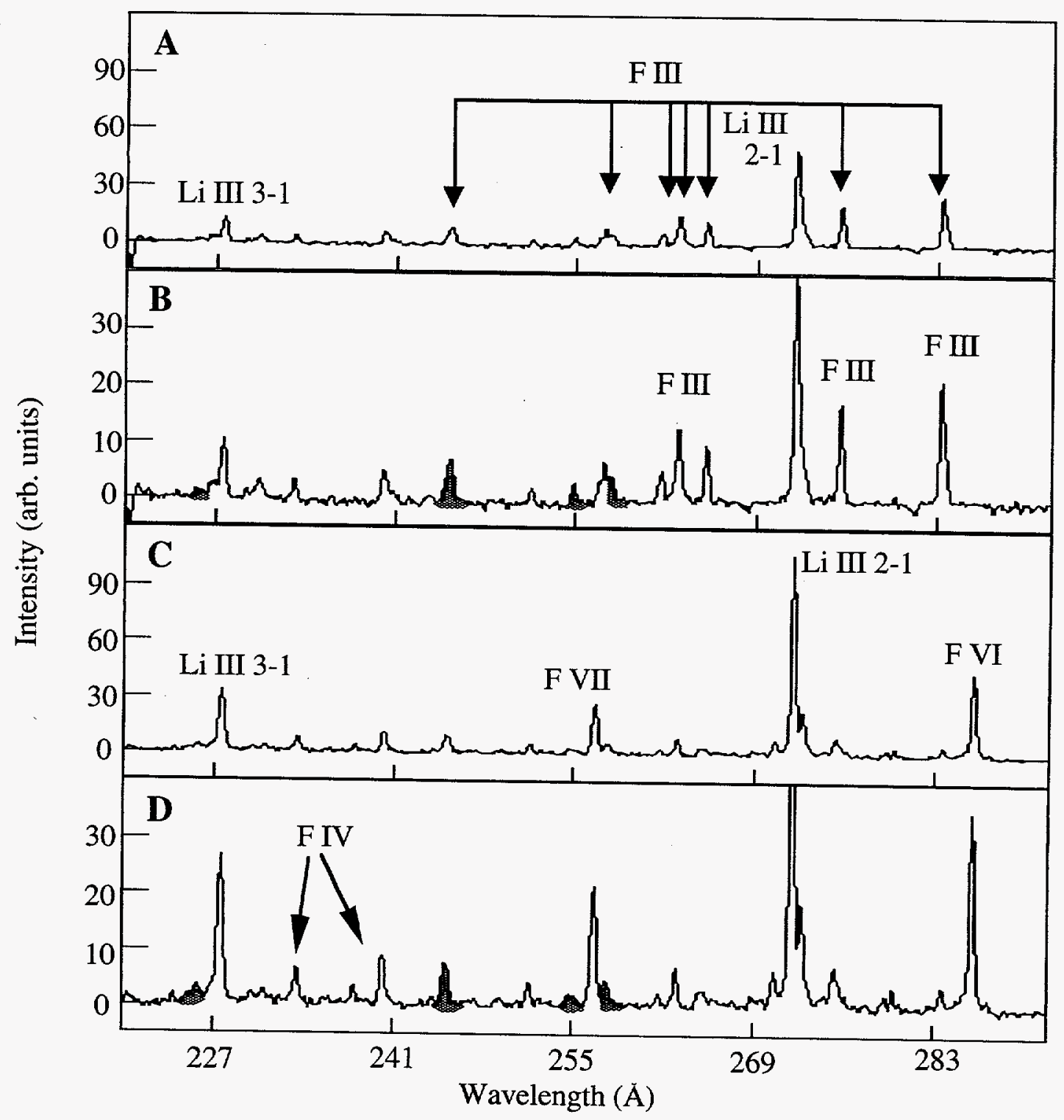

Figure 8. 


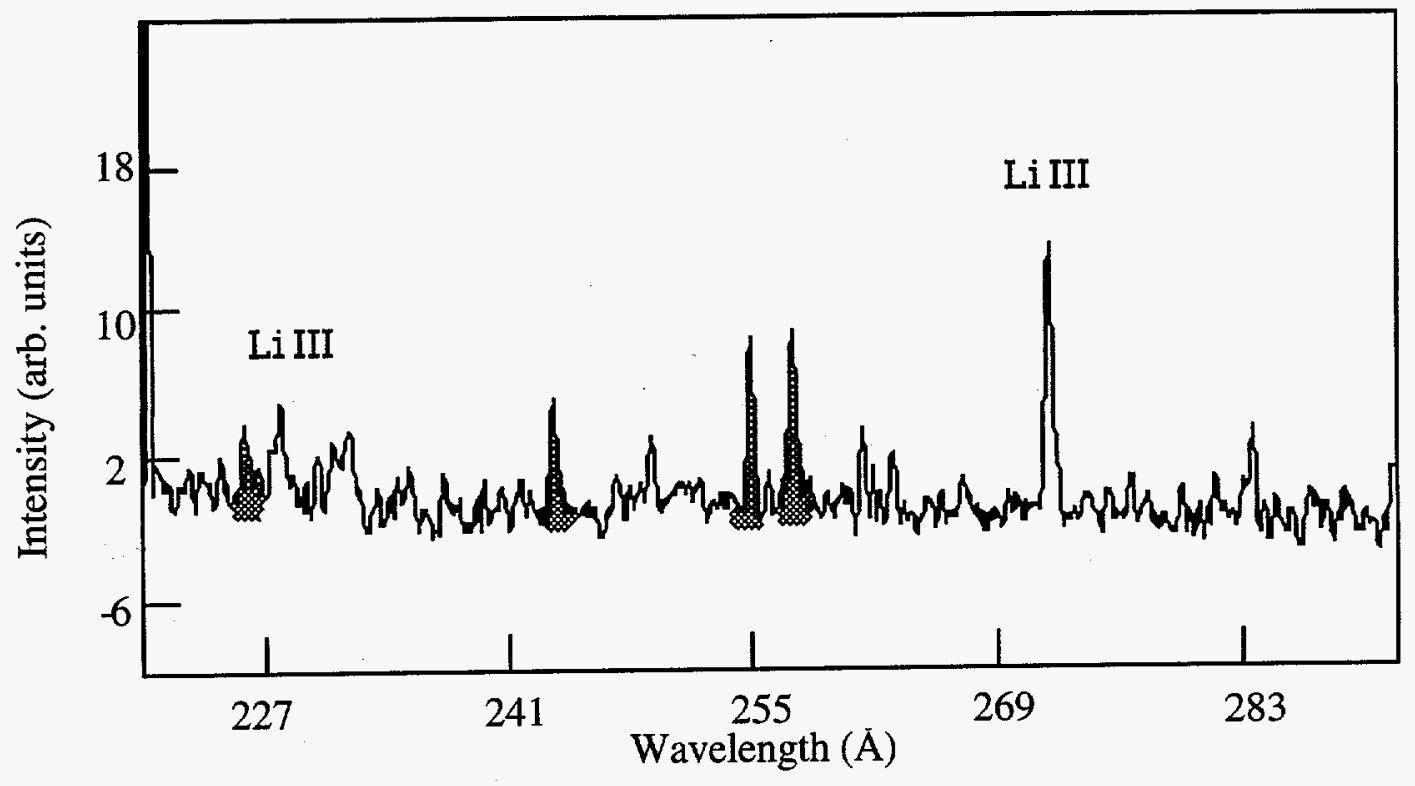

Figure 9. 
Dr. F. Paoloni, Univ. of Wollongong, AUSTRALIA

Prof. R.C. Cross, Univ. of Sydney, AUSTRALIA

Plasma Research Lab., Australian Nat. Univ., AUSTRALIA

Prof. I.R. Jones, Flinders Univ, AUSTRALIA

Prof. F. Cap, Inst. for Theoretical Physics, AUSTRIA

Prof. M. Heindler, Institut für Theoretische Physik, AUSTRIA

Prof. M. Goossens, Astronomisch Instituut, BELGIUM

Ecole Royale Militaire, Lab. de Phy. Plasmas, BELGIUM

Commission-European, DG. XII-Fusion Prog., BELGIUM

Prof. R. Bouciqué, Rijksuniversiteit Gent, BELGIUM

Dr. P.H. Sakanaka, Instituto Fisica, BRAZIL

Prof. Dr. I.C. Nascimento, Instituto Fisica, Sao Paulo, BRAZIL Instituto Nacional De Pesquisas Espaciais-INPE, BRAZIL

Documents Office, Atomic Energy of Canada Ltd., CANADA

Ms. M. Morin, CCFMTokamak de Varennes, CANADA

Dr. M.P. Bachynski, MPB Technologies, Inc., CANADA

Dr. H.M. Skarsgard, Univ. of Saskatchewan, CANADA

Prof. J. Teichmann, Univ. of Montreal, CANADA

Prof. S.R. Sreenivasan, Univ. of Calgary, CANADA

Prof. T.W. Johnston, INRS-Energie, CANADA

Dr. R. Bolton, Centre canadien de fusion magnétique, CANADA

Dr. C.R. James, Univ. of Alberta, CANADA

Dr. P. Lukác, Komenského Universzita, CZECHO-SLOVAKIA

The Librarian, Culham Laboratory. ENGLAND

Library, R61, Rutherford Appleton Laboratory, ENGLAND

Mrs. S.A. Hutchinson, JET Library, ENGLAND

Dr. S.C. Sharma, Univ. of South Pacific, FIJI ISLANDS

P. Mähönen, Univ. of Helsinki, FINLAND

Prof. M.N. Bussac, Ecole Polytechnique, FRANCE

C. Mouttel, Lab. de Physique des Milieux lonisés, FRANCE

J. Radet, CEN/CADARACHE - Bat 506, FRANCE

Prof. E. Economou, Univ. of Crete, GREECE

Ms. C. Rinni, Univ. of loannina, GREECE

Preprint Library, Hungarian Academy of Sci., HUNGARY

Dr. B. DasGupta, Saha Inst. of Nuclear Physics, INDIA

Dr. P. Kaw, Inst. for Plasma Research, INDIA

Dr. P. Rosenau, Israel Inst. of Technology, ISRAEL

Librarian, International Center for Theo Physics, ITALY

Miss C. De Palo, Associazione EURATOM-ENEA, ITALY

Dr. G. Grosso, Istituto di Fisica del Plasma, ITALY

Prof. G. Rostangni, Istituto Gas lonizzati Del Cnr, ITALY
Dr. H. Yamato, Toshiba Res \& Devel Center, JAPAN

Prof. I. Kawakami, Hiroshima Univ., JAPAN

Prof. K. Nishikawa, Hiroshima Univ., JAPAN

Librarian, Naka Fusion Research Establishment, JAERI, JAPAN

Director, Japan Atomic Energy Research Inst., JAPAN

Prof. S. Itoh, Kyushu Univ., JAPAN

Research Info. Ctr., National Instit. for Fusion Science, JAPAN

Prof. S. Tanaka, Kyoto Univ., JAPAN

Library, Kyoto Univ., JAPAN

Prot. N. Inove, Univ. of Tokyo, JAPAN

Secretary, Plasma Section, Electrotechnical Lab., JAPAN

Dr. O. Mitarai, Kumamoto Inst. of Technology, JAPAN

Dr. G.S. Lee, Korea Basic Sci. Ctr., KOREA

J. Hyeon-Sook, Korea Atomic Energy Research Inst., KOREA

D.I. Choi, The Korea Adv. Inst. of Sci. \& Tech., KOREA

Prof. B.S. Liley, Univ. of Waikato, NEW ZEALAND

Inst of Physics, Chinese Acad Sci PEOPLE'S REP. OF CHINA

Library, Inst. of Plasma Physics, PEOPLE'S REP. OF CHINA

Tsinghua Univ. Library, PEOPLE'S REPUBLIC OF CHINA

Z. Li, S.W. Inst Physics, PEOPLE'S REPUBLIC OF CHINA

Prof. J.A.C. Cabral, Instituto Superior Tecnico, PORTUGAL

Prof. M.A. Hellberg, Univ. of Natal, S. AFRICA

Prof. D.E. Kim, Pohang inst. of Sci. \& Tech., SO. KOREA

Prof. C.I.E.M.A.T, Fusion Division Library, SPAIN

Dr. L. Stenflo, Univ. of UMEA, SWEDEN

Library, Royal Inst. of Technology, SWEDEN

Prof. H. Wilhelmson, Chalmers Univ. of Tech., SWEDEN

Centre Phys. Des Plasmas, Ecole Polytech, SWITZERLAND

Bibliotheek, Inst. Voor Plasma-Fysica, THE NETHERLANDS

Asst. Prof. Dr. S. Cakir, Middle East Tech. Univ., TURKEY

Dr. V.A. Glukhikh,Sci. Res. Inst. Electrophys.I Apparatus, USSR

Dr. D.D. Ryutov, Siberian Branch of Academy of Sci., USSR

Dr. G.A. Eliseev, I.V. Kurchatov Inst., USSR

Librarian, The Ukr.SSR Academy of Sciences, USSR

Dr. L.M. Kovizhnykh, Inst. of General Physics, USSR

Kernforschungsanlage GmbH, Zentralbibliothek, W. GERMANY

Bibliothek, Inst. Für Plasmaforschung, W. GERMANY

Prof. K. Schindler, Ruhr-Universitát Bochum, W. GERMANY

Dr. F. Wagner, (ASDEX), Max-Planck-institut, W. GERMANY

Librarian, Max-Planck-Institut, W. GERMANY 